\title{
BMJ
}

\section{Emotional distress in infertile women and failure of assisted reproductive technologies: meta-analysis of prospective psychosocial studies}

\section{J Boivin, professor and health psychologist, ${ }^{1}$ E Griffiths, assistant clinical psychologist, ${ }^{2}$ C A Venetis, research fellow ${ }^{3}$}

${ }^{1}$ Cardiff Fertility Studies Research Group, School of Psychology, Cardiff University, Cardiff, UK ${ }^{2}$ The Lawns Resource Centre, The Baulk, Biggleswade, UK

${ }^{3}$ Unit for Human Reproduction, 1st Department of Obstetrics and

Gynaecology, Aristotle University of Thessaloniki, Thessaloniki, Greece

Correspondence to: J Boivin, Cardiff Fertility Studies Research Group,

School of Psychology, Cardiff University, Tower Building, Park

Place, Cardiff, UK

boivin@cardiff.ac.uk

Cite this as: $B M J$ 2011;342:d223 doi:10.1136/bmj.d223

\section{ABSTRACT}

Objective To examine whether pretreatment emotional distress in women is associated with achievement of pregnancy after a cycle of assisted reproductive technology.

Design Meta-analysis of prospective psychosocial studies.

Data sources PubMed, Medline, Embase, PsycINFO, PsychNET, ISI Web of Knowledge, and ISI Web of Science were searched for articles published from 1985 to March 2010 (inclusive). We also undertook a hand search of reference lists and contacted 29 authors. Eligible studies were prospective studies reporting a test of the association between pretreatment emotional distress (anxiety or depression) and pregnancy in women undergoing a single cycle of assisted reproductive technology.

Review methods Two authors independently assessed the studies for eligibility and quality (using criteria adapted from the Newcastle-Ottawa quality scale) and extracted data. Authors contributed additional data not included in original publication.

Results Fourteen studies with 3583 infertile women undergoing a cycle of fertility treatment were included in the meta-analysis. The effect size used was the standardised mean difference (adjusted for small sample size) in pretreatment anxiety or depression (priority on anxiety where both measured) between women who achieved a pregnancy (defined as a positive pregnancy test, positive fetal heart scan, or live birth) and those who did not. Pretreatment emotional distress was not associated with treatment outcome after a cycle of assisted reproductive technology (standardised mean difference $-0.04,95 \%$ confidence interval -0.11 to 0.03 (fixed effects model); heterogeneity $\mathrm{l}^{2}=14 \%, \mathrm{P}=0.30$ ). Subgroup analyses according to previous experience of assisted reproductive technology, composition of the not pregnant group, and timing of the emotional assessment were not significant. The effect size did not vary according to study quality, but a significant subgroup analysis on timing of the pregnancy test, a contour enhanced funnel plot, and Egger's test indicated the presence of moderate publication bias.
Conclusions The findings of this meta-analysis should reassure women and doctors that emotional distress caused by fertility problems or other life events cooccurring with treatment will not compromise the chance of becoming pregnant.

\section{INTRODUCTION}

Infertility affects $9 \%$ to $15 \%$ of the childbearing population, ${ }^{1}$ and $55 \%$ of those affected will seek medical advice in the hope of achieving parenthood. ${ }^{2}$ Many infertile women believe that emotional distress (for example, tension or worry) is a contributing factor to their lack of natural fertility and lack of success with fertility treatment. ${ }^{3}$ These beliefs are usually based on anecdotal evidence and oft repeated fertility myths of spontaneous conception after holidays ("relax and you'll get pregnant") or after adoption when couples no longer have the strain of trying to conceive ("don't think about it and you'll get pregnant"). In contrast, doctors tend to consider the contribution of stress to be negligible ${ }^{4}$ because of inconclusive results in the empirical literature.

Assisted reproductive technologies like in vitro fertilisation and intracytoplasmic sperm injection are complex and stressful, and are therefore the subject of many studies investigating emotional distress and outcome of fertility treatment. The use of assisted reproductive technologies is implicated in $1.6 \%$ of births in Britain, ${ }^{5}$ with 35000 women treated every year in the United Kingdom. ${ }^{6}$ A cycle of in vitro fertilisation typically requires nine to 12 days of self injection with potent fertility drugs to stimulate the production of oocytes (eggs), retrieval of oocytes via transvaginal ultrasonography, fertilisation of oocytes in the laboratory with partner or donor sperm, and transfer of the resulting embryo to the uterus. Couples then wait two to three weeks to find out whether implantation and a pregnancy have occurred.

Patients expect assisted reproductive technologies to be stressful, ${ }^{7}$ and $30 \%$ of couples end treatment prematurely because of its psychological burden. ${ }^{8}$ The contribution of biological, reproductive, and lifestyle factors to the success or failure of fertility treatment is 
well established, ${ }^{9}$ but the influence of emotional distress is inconclusive because of mixed results in psychosocial studies. Emotional distress would likely exert its effect on the chance of pregnancy by compromising ovarian function ${ }^{10}$ or implantation, ${ }^{11}$ because stress induced suppression in these phases of the reproductive event is physiologically less costly than disruptions at a later point in pregnancy. ${ }^{12}$

The lack of consensus in psychosocial studies examining the effect of emotional distress is likely to be owing to heterogeneity in study designs. For example, $60 \%$ of spontaneous conceptions are lost within two weeks of fertilisation, ${ }^{13}$ but psychosocial studies measure women at different stages of pregnancy (for example, at two, six, or 12 weeks of pregnancy, or at delivery) and often group together patients with different causes of treatment failure (for example, lack of oocytes or failure of implantation). The magnitude of the response of the hypothalamic-pituitary-adrenal axis to stress decreases over repeated exposures to the same stressor, ${ }^{14}$ and so does the inhibitory effect of stress on fertility (for example, disruption of luteinising hormone). ${ }^{15}$ However, psychosocial studies vary in the sampling of first time versus experienced patients, producing heterogeneity in treatment familiarity and distress ratings. The effect of emotional distress could be missed in some psychosocial studies because of the long interval between emotional assessments and the start of treatment, because stress is higher closer to the onset of a stressful event. ${ }^{16}$ Finally, variations in other design features (for example, length of follow-up and statistical power) could also contribute to mixed findings in this body of work.

A meta-analysis taking into account these issues could help achieve greater certainty about the association between emotional distress and pregnancy. To our knowledge the only previous published meta-analyses on this topic are doctoral dissertations that produced inconclusive results. ${ }^{1718}$ For this reason, we conducted a comprehensive review and meta-analysis of prospective studies that assessed emotional distress before the start of a fertility treatment cycle and that compared these emotional ratings in women who subsequently became pregnant and those who did not become pregnant from their cycle. We also examined whether this association varied as a function of the aforementioned design characteristics to examine potential causes of inconsistency in this body of evidence.

\section{METHODS}

Identification and selection of studies

EG executed a computerised search of PubMed, Medline, Embase, PsycINFO, PsychNET, ISI Web of Knowledge, and ISI Web of Science for articles published between 1985 and March 2010 (inclusive). The search terms were: "in vitro fertilization," "in vitro fertilisation," "IVF," "assisted reproduction," "intracytoplasmic sperm injection," "ICSI," and "assisted reproductive techniques"; AND "psychological stress," "depressive disorder," "anxiety," "anxiety disorder," "adjustment disorder," “emotions," "psychosomatic medicine," "psychological adaptation," "distress," and "depression". MeSH terms were used in PubMed. We did not impose any restriction on the type of publication (journal, conference paper, or dissertation) or language of publication. Non-English publications were reviewed with the help of colleagues. Proceedings of fertility conferences were examined where proceedings are available in computerised databases (for example, European Society of Human Reproduction and Embryology). A comprehensive examination of the reference sections of all identified articles was carried out. All citations were transferred to EndNote (Thomson Reuters, San Francisco, CA).

Selection criteria, data extraction, and quality assessment JB and EG selected the studies. The selection criteria were that emotional distress (anxiety or depression) in women was measured before the start of stimulation; the outcome (pregnant or not pregnant) was reported for a single cycle of treatment with an assisted reproductive technology (in vitro fertilisation, intracytoplasmic sperm injection, or gamete intrafallopian transfer); the pregnancy outcome was based on laboratory or clinical evidence; and means and standard deviations for pretreatment emotional distress (anxiety or depression) were available for pregnant and not pregnant groups in the publication or through additional contact with the author.

Emotional assessment before stimulation was required because blood tests and scans to calibrate stimulation drugs can confound anxiety and depression ratings, especially in women who require a higher dose because of poor response to treatment. ${ }^{7} \mathrm{We}$ only included studies that used anxiety or depression as indicators of emotional distress because these measures are reliably related to stress induced activation of the hypothalamic-pituitary-adrenal axis. ${ }^{19}$ Outcome for a single cycle of treatment was used to control for between study variation in number of cycles and duration of treatment period. Furthermore, by considering eligible studies in which patients did not contribute more than one treatment cycle, it was assured that the assumption of independence of observations had not been violated.

Duplicate or secondary publications on the same sample (for example, Smeenk et $\mathrm{al}^{11}$ and Verhaak et $\mathrm{al}^{20}$ ) were excluded from the meta-analysis to avoid multiple publication bias. In cases where there were multiple publications, we used the publication that contained means and standard deviations for the largest sample from the group. Excluded studies were classified according to reason for exclusion. JB and EG agreed inclusion of all but one study (excluded after discussion) and agreed on reasons for exclusion for $98.2 \%$ of studies (details of exclusions can be obtained from the corresponding author).

Data from each study were extracted by EG and JB, and they agreed all entries. The following data were extracted (where available): publication date; country; sample size; average age and duration of infertility in the study sample; whether the sample included women 
Studies identified 1985 to March $2010(n=1175)$

Excluded $(n=1161)$

By title $(n=972)$

By abstract $(n=152)$

By text $(n=37)$

Studies included $(n=14)$

Fig 1 | Decision flowchart for identified studies

with previous experience of assisted reproductive technologies (yes or no; if yes, the proportion of the sample with experience); method for assessment of distress; and definition of pregnancy for the assisted reproductive cycle. Evidence of pregnancy was classified according to a positive pregnancy test, if based on a $\beta$-human chorionic gonadotrophin urine or blood test $\leq 21$ days after embryo transfer, or a positive fetal scan if based on ultrasonographic visualisation of fetal heart activity or live birth, as per standard definitions. ${ }^{21}$ The composition of the "not pregnant" group in each study was coded to indicate whether this group included all patients that initiated a cycle and failed to get pregnant or whether it included only those who at least reached embryo transfer and failed to get pregnant (that is, the latter excluded women whose cycle was cancelled before transfer because of a poor ovarian response to stimulation or failed fertilisation).

$\mathrm{JB}$ and $\mathrm{CV}$ assessed study quality according to the Newcastle-Ottawa quality assessment scale, ${ }^{22}$ which evaluates quality in terms of selection of participants, measurement of emotional distress, comparability of groups on confounders, and comparability of groups on outcome and follow-up. Points were awarded if: $(a)$ the study sample was representative of patients using assisted reproductive technologies (that is, more than $80 \%$ of eligible patients were invited and more than $80 \%$ agreed to participate, or sample size was more than 300 (corresponds to $80 \%$ of average yearly patient enrolment in most European assisted reproductive technology clinics) (1 point)); (b) the study reliably measured distress (that is, the study used a standard, reliable, and valid measurement tool with respect to its psychometric properties ${ }^{23}$ and classification of the tool in a recent meta-analysis on psychological inter ventions $^{24}$ (1 point)); (c) the study groups were comparable on confounders (that is, at study entry, subsequently pregnant and not pregnant groups were comparable (not significantly different) on the prognostic indicators ${ }^{9}$ of age, previous use of assisted reproductive technology, parity, and duration of infertility (2 points) or comparable on at least two of these indicators ( 1 point $)$ ); and $(d)$ the study had adequate outcome and follow-up (that is, when the completion rate (number of people who agreed to participate divided by the number analysed) for patients undergoing the cycle was more than $80 \%$ (1 point)). The overall quality rating was the sum of met criteria (maximum five). Low, moderate, and high quality labels were assigned to scores of 0-2, 3, 4-5, respectively. Inter-rater agreement for quality ratings was excellent (Cohen's $\kappa=0.951$, $\mathrm{P}<0.001)$.

\section{Data synthesis and analysis}

The primary outcome measure was the standardised mean difference in pretreatment anxiety or depression between the group that achieved pregnancy with the assisted reproductive technology and the group that did not, adjusted for small sample size using Hedges's $g$ correction. ${ }^{25}$ Effect sizes were aligned across studies so that a negative standardised mean difference indicated more emotional distress (depression or anxiety) in the subsequently not pregnant group. Only one effect size was returned per study to create an independent set of effect sizes for emotional distress. If studies used multiple measures, then we prioritised state anxiety because it reflects emotional state of the moment, compared with trait anxiety, ${ }^{26}$ and it is sensitive to anticipatory emotional reactions (for example, tension, worry), whereas depression is more sensitive to emotions arising from the outcome of treatment (for example, sadness, feelings of loss). ${ }^{2728}$ However, depression was used in studies that did not measure anxiety.

A fixed effects model was adopted on the assumption that study samples were drawn from the same population and therefore estimated the same effect size. In the presence of statistically significant heterogeneity, a random effects model was used. Furthermore, subgroup analyses were performed on the basis of specific methodological and clinical characteristics of the studies, which were defined a priori (for example, timing of psychological assessment, operational definition of pregnancy, past use of an assisted reproductive technology, composition of the not pregnant group). The inverse variance method was used to pool the standardised mean difference. Homogeneity of the effect size distribution was tested using the Q statistic, ${ }^{29}$ and the $\mathrm{I}^{2}$ index was used to assess the proportion of effect size variability that was owing to non-chance factors. ${ }^{30}$ Regarding subgroup analyses, the pooled effect sizes of each subgroup were compared to identify potential significant differences in the direction or magnitude of the effect. Furthermore, differences between subgroups were assessed using the $\chi^{2}$ test, as implemented in the ReviewManager software.

Publication bias was checked with visual inspection of contour enhanced funnel plots ${ }^{31}$ and the Egger's test, ${ }^{32}$ with the slope of the regression (bias coefficient) indicating the extent of any bias. Publication bias was further assessed by application of the trim and fill method. Trim and fill is an iterative non-parametric method used to investigate the number of "missing" studies in a meta-analysis, as indicated by funnel plot asymmetry, and calculates an adjusted pooled estimate with the addition of those "missing" studies. ${ }^{33}$ The probability level of $\mathrm{P}<0.05$ was used to indicate statistical significance.

We used ReviewManager version 5.0.24 (Nordic Cochrane Centre, Copenhagen, Denmark) to calculate all effect sizes, and for the meta-analysis and forest plots. Stata (StataCorp, College Station, TX) was used 
for the Egger's test, the trim and fill method, and the construction of the contour enhanced funnel plot.

\section{RESULTS}

\section{Description of studies}

The database and manual search yielded 1175 nonduplicated records that contained the relevant psychological and reproductive search terms, but 1161 $(98.8 \%)$ did not meet inclusion criteria and were excluded (fig 1). The main reasons for exclusion were that the study was not relevant $(597,50.8 \%)$, did not test the relationship between distress and pregnancy $(215$, $18.3 \%)$, or did not contain primary quantitative data $(186,15.8 \%)$. We contacted 29 authors to obtain unpublished work (including unpublished dissertations) and additional data, which was successful in all but three cases.

Table 1 shows that the 14 included studies sampled 3583 women in 10 countries. The range across studies for average age was 29.7 to 36.8 years and for duration of infertility 2.6 to 7.8 years. Three studies sampled patients that had never used an assisted reproductive technology, and 11 studies included a mixed sample of patients with and without past use of an assisted reproductive technology. Table 2 shows the design features of the studies. The data collection period across studies was from 1992 to 2006 (four studies did not report the data collection period). The most commonly used measure of emotional distress was the Spielberger state-trait anxiety inventory, which is a reliable and validated measure of state anxiety. ${ }^{2324}$ Distress was most frequently assessed within a month of the treatment cycle (6/14 studies; three did not specify). Pregnancy was operationally defined as a positive fetal heart scan (clinical pregnancy) in eight studies, positive pregnancy test in four studies (preclinical pregnancy), and a live birth in two studies. In six of the 14 studies, all women who initiated the cycle but failed to get pregnant were included in the not pregnant group, whereas in eight studies only women who at least underwent embryo transfer were included.

Table 3 shows the modified Newcastle-Ottawa quality ratings for each study (for full details on each quality indicator see the supplemental web table on bmj.com). Participant selection in seven studies met the criteria for having a truly or somewhat representative sample, with the remaining studies using non-consecutive recruitment (that is, doctor referral to study ${ }^{734-36}$ or a selected patient group $\left.{ }^{37-40}\right)$. The reliability quality criterion was met in 13studies, which all used a recog nised reliable and valid measure of emotional distress. Three studies showed comparability of groups at study entry on all four key confounders of age, previous use of assisted reproductive technology, parity, and duration of infertility. Follow-up showed completion rates above $80 \%$ for 11 studies (after exclusion of participants who did not start the cycle because of becoming pregnant on the waiting list or deciding against using assisted reproductive technologies). Twelve studies were published in a peer reviewed journal and two in conference abstracts. ${ }^{3741}$ Total quality ratings indicated five low quality studies, three average studies, and six high quality studies.

\section{Meta-analysis}

Figure 2 shows the pooled standardised mean differences in pretreatment emotional distress between the subsequently pregnant and not pregnant groups for the fixed effects model. The meta-analysis showed a non-significant overall effect size of distress on the likelihood of pregnancy $(-0.04,95 \% \mathrm{CI}-0.11$ to 0.03$)$, with non-significant heterogeneity between studies $\left(\mathrm{I}^{2}=14 \%, \mathrm{P}=0.30\right)$. Sensitivity analysis using a random effects model produced similar results, with a pooled effect size of -0.05 (95\% CI -0.14 to 0.03$)$.

\section{Subgroup analyses}

Regarding the subgroup analyses, no statistically significant differences were observed between subgroups

Table 1|Sample characteristics reported in the 14 included studies

\begin{tabular}{|c|c|c|c|c|c|c|}
\hline & Country & $\begin{array}{l}\text { Women who got } \\
\text { pregnant (n) }\end{array}$ & $\begin{array}{l}\text { Women who did not } \\
\text { get pregnant }(n)\end{array}$ & $\begin{array}{c}\text { Age of women } \\
\text { (years; mean (SD)) }\end{array}$ & $\begin{array}{l}\text { Duration of infertility } \\
\text { (years; mean (SD)) }\end{array}$ & $\begin{array}{c}\text { Previously used assisted reproductive } \\
\text { technologies (yes/no (\%)) }\end{array}$ \\
\hline Akyuz et al $2006^{37 *}$ & Turkey & 39 & 41 & - & - & Yes $(60 \%)$ \\
\hline Anderheim et al $2005^{47}$ & Sweden & 58 & 81 & $32.1(3.6)$ & $4.5(2.4)$ & Yes (7.24\%) \\
\hline Boivin and Takefman $1995^{7}$ & Canada & 17 & 23 & $33.3(3.6)$ & $4.4(2.1)$ & No \\
\hline de Klerk et al $2008^{40}$ & Netherlands & 73 & 216 & $32.8(3.1)$ & $3.6(1.9)$ & Yes $(6 \%) \dagger$ \\
\hline Demyttenaere et al $1992^{36}$ & Belgium & 10 & 30 & $32.4(4.1)$ & $5.6(2.6)$ & Yes (57.50\%) \\
\hline Demyttenaere et al $1998^{35}$ & Belgium & 23 & 75 & $29.7(3.5)$ & $4.1(3.1)$ & Yes (43.88\%) \\
\hline Ebbesen et al $2009^{48}$ & Denmark & 215 & 566 & $31.2(3.9)$ & $2.6(1.9)$ & No \\
\hline Klonoff-Cohen et al $2001^{39}$ & USA & 46 & 90 & $36.8(4.3)$ & $4.1(3.0)$ & Yes (37\%) \\
\hline Lancastle and Boivin $2005^{10}$ & UK & 13 & 63 & $33.3(3.3)$ & $7.8(3.0)$ & Yes $(35.05 \%)$ \\
\hline Lee et al $2006^{41}$ & USA & 364 & 440 & - & $3.2(2.4)$ & Yes $(-)$ \\
\hline Lintsen et al $2009^{49}$ & Netherlands & 196 & 494 & $33.2(3.5)$ & $3.4(1.8)$ & No \\
\hline Merari et al $2002^{38}$ & Israel & 23 & 90 & $33.9(5.3)$ & $7.2(4.9)$ & Yes $(-)$ \\
\hline Sanders and Bruce $1999^{34}$ & Australia & 15 & 75 & $32.6(4.4)$ & - & Yes $(23.30 \%)$ \\
\hline Verhaak et al $2001^{20}$ & Netherlands & 59 & 148 & $33.4(3.7)$ & $3.7(2.0)$ & Yes (12.5\%) \\
\hline
\end{tabular}

* $51.2 \%$ were $31-35$ years of age, and duration of infertility was $2-7$ years for $61 \%$.

†All participants with previous use of an assisted reproductive technology had had a live birth. 
Table $2 \mid$ Characteristics of the design of the 14 included studies

\begin{tabular}{|c|c|c|c|c|c|c|}
\hline & $\begin{array}{l}\text { Data collection } \\
\text { period }\end{array}$ & Population & Measure of emotional distress & $\begin{array}{l}\text { Timing of assessment } \\
\text { for emotional distress }\end{array}$ & $\begin{array}{l}\text { Operational } \\
\text { definition of } \\
\text { pregnancy* }\end{array}$ & $\begin{array}{c}\text { Composition of } \\
\text { not pregnant } \\
\text { group } \dagger\end{array}$ \\
\hline Akyuz et al $2006^{37}$ & 2004 to 2005 & $\begin{array}{l}\text { Unexplained, only } \\
\text { intracytoplasmic sperm injection }\end{array}$ & $\begin{array}{l}\text { Spielberger state-trait anxiety } \\
\text { inventory }\end{array}$ & Beginning of cycle & Positive test & With transfer \\
\hline Anderheim et al $2005^{47}$ & 1999 to 2002 & Consecutive patients & $\begin{array}{l}\text { Psychological general wellbeing: } \\
\text { anxiety subscale }\end{array}$ & 1 month before treatment & Positive scan & With transfer \\
\hline $\begin{array}{l}\text { Boivin and Takefman } \\
1995^{7}\end{array}$ & 1992 to 1994 & Referred by doctor, first time users & $\begin{array}{l}\text { Spielberger state-trait anxiety } \\
\text { inventory }\end{array}$ & $\begin{array}{l}>1.8 \text { months before } \\
\text { treatment }\end{array}$ & Positive test & With transfer \\
\hline de Klerk et al $2008^{40}$ & 2002 to 2004 & $\begin{array}{l}\text { Consecutive patients, single } \\
\text { embryo transfer }\end{array}$ & $\begin{array}{l}\text { Hospital anxiety and depression } \\
\text { scale: anxiety subscale }\end{array}$ & 6 weeks before treatment & Live birth & With transfer \\
\hline Demyttenaere et al $1992^{36}$ & Not reported & Consecutive patients & Zung depression inventory & Day 4 to 5 of cycle & Positive test & All \\
\hline Demyttenaere et al $1998^{35}$ & Not reported & $\begin{array}{l}\text { Referred by doctor, primary } \\
\text { infertility }\end{array}$ & Zung depression inventory & Day 3 of cycle & Positive scan & All \\
\hline Ebbesen et al $2009^{48}$ & 2001 to 2006 & $\begin{array}{l}\text { Consecutive patients, first time } \\
\text { users }\end{array}$ & Beck depression inventory II & Before first scan & Positive scan & With transfer \\
\hline Klonoff-Cohen etal $2001^{39}$ & 1993 to 1998 & Patients & $\begin{array}{l}\text { Profile of moods scale (unipolar): } \\
\text { anxiety }\end{array}$ & Before first visit & Live birth & With transfer \\
\hline $\begin{array}{l}\text { Lancastle and Boivin } \\
2005^{10}\end{array}$ & 1995 to 1997 & Consecutive patients & $\begin{array}{l}\text { Spielberger state-trait anxiety } \\
\text { inventory }\end{array}$ & $\begin{array}{l}2.8 \text { months before } \\
\text { treatment }\end{array}$ & Positive test & With transfer \\
\hline Lee et al $2006^{41}$ & Not reported & Patients & $\begin{array}{l}\text { Center for Epidemiologic Studies } \\
\text { depression scale }\end{array}$ & Day 3 of cycle & Positive scan & All \\
\hline Lintsen et al $2009^{49}$ & 2002 to 2004 & $\begin{array}{l}\text { Consecutive patients, first time } \\
\text { users }\end{array}$ & $\begin{array}{l}\text { Spielberger state-trait anxiety } \\
\text { inventory }\end{array}$ & $\begin{array}{l}1 \text { to } 2 \text { months before } \\
\text { treatment }\end{array}$ & Positive scan & With transfer \\
\hline Merari et al $2002^{38}$ & Not reported & $\begin{array}{l}\text { Consecutive, unexplained } \\
\text { infertility/tubal, primary infertility }\end{array}$ & $\begin{array}{l}\text { Spielberger state-trait anxiety } \\
\text { inventory }\end{array}$ & $\begin{array}{c}10 \text { to } 15 \text { days before } \\
\text { treatment }\end{array}$ & Positive scan & All \\
\hline Sanders and Bruce $1999^{34}$ & 1990 to 1993 & New patients & $\begin{array}{l}\text { Spielberger state-trait anxiety } \\
\text { inventory }\end{array}$ & $\begin{array}{c}1 \text { to } 3 \text { months before } \\
\text { treatment }\end{array}$ & Positive scan & All \\
\hline Verhaak et al $2001^{20}$ & 1999 & Consecutive patients & $\begin{array}{l}\text { Spielberger state-trait anxiety } \\
\text { inventory }\end{array}$ & $\begin{array}{l}3 \text { to } 10 \text { days before } \\
\text { treatment }\end{array}$ & Positive scan & All \\
\hline
\end{tabular}

*Positive test=positive pregnancy test; positive scan=positive fetal ultrasound scan.

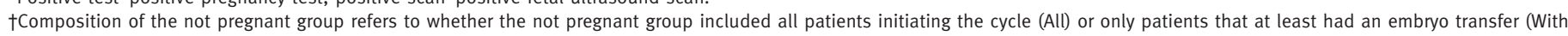
transfer).

for timing of the emotional assessment $(\mathrm{P}=0.66)$, previous use of assisted reproductive technology $(\mathrm{P}=0.66)$, and composition of the not pregnant group $(\mathrm{P}=0.39)$. Specifically, the effect size for studies that undertook emotional assessment within one month of the treatment cycle $(\mathrm{n}=6$; standardised mean difference -0.01 , $95 \% \mathrm{CI}-0.12$ to 0.10 ; heterogeneity $\mathrm{I}^{2}=37 \%, \mathrm{P}=0.16$ ) was similar to that for studies that did emotional assessment more than one month before treatment $(\mathrm{n}=5$; $-0.05,95 \%$ CI -0.18 to $0.08 ; \mathrm{I}^{2}=0 \%, \mathrm{P}=0.55$ ). Three studies did not specify precisely when emotional assessment took place. ${ }^{35-37}$ The effect size was comparable for studies that included first time users of assisted reproductive technologies $(\mathrm{n}=3 ;-0.02,95 \% \mathrm{CI}-0.13$ to $\left.0.09 ; \mathrm{I}^{2}=0 \%, \mathrm{P}=0.59\right)$ and studies that had a mixed sample of repeat and first time patients $(\mathrm{n}=11 ;-0.05$, $95 \% \mathrm{CI}-0.15$ to $\left.0.04 ; \mathrm{I}^{2}=28 \%, \mathrm{P}=0.18\right)$. The studies that included only not pregnant women who had undergone embryo transfer had a greater, although not significantly so, effect size $(\mathrm{n}=8 ;-0.06,95 \%$ CI -0.16 to $\left.0.03 ; \mathrm{I}^{2}=0 \%, \mathrm{P}=0.43\right)$ than studies that included all initiated patients who did not become pregnant $\left(\mathrm{n}=6 ;-0.00,95 \% \mathrm{CI}-0.11\right.$ to $0.11 ; \mathrm{I}^{2}=33 \%$, $\mathrm{P}=0.19$ ). The subgroup analysis according to definition of pregnancy detected a significant difference between the two subgroups $(\mathrm{P}=0.006)$. Studies that used a positive pregnancy test to define a pregnancy had a significant pooled standardised mean difference that showed more distress in subsequently not pregnant women than in those who did get pregnant $(\mathrm{n}=4 ;-0.42,95 \%$ $\mathrm{CI}-0.71$ to $-0.14 ; \mathrm{I}^{2}=0 \%, \mathrm{P}=0.97$ ), whereas no difference between groups was detected in studies that defined pregnancy as a positive fetal scan or live birth $\left(\mathrm{n}=10 ;-0.01,95 \% \mathrm{CI}-0.09\right.$ to $\left.0.06 ; \mathrm{I}^{2}=0 \%, \mathrm{P}=0.59\right)$.

\section{Study quality and publication bias}

We performed a subgroup analysis according to study quality (that is, low, average, or high), and this analysis was not significant $(\mathrm{P}=0.79)$. Effect size was similar for the low quality category $(\mathrm{n}=5$; standardised mean difference $-0.04,95 \% \mathrm{CI}-0.16$ to 0.08 ; heterogeneity $\left.\mathrm{I}^{2}=42 \%, \quad \mathrm{P}=0.14\right)$, average quality category $(\mathrm{n}=3$; $-0.10,95 \% \mathrm{CI}-0.30$ to $\left.0.10 ; \mathrm{I}^{2}=22 \%, \mathrm{P}=0.28\right)$, and high quality category $(\mathrm{n}=6 ;-0.02,95 \% \mathrm{CI}-0.12$ to $\left.0.08 ; \mathrm{I}^{2}=3 \%, \mathrm{P}=0.40\right)$. The contour enhanced funnel plot (fig 3) showed evidence of asymmetry. The oval red area, where "missing" studies would be expected in order to correct for the visually detected asymmetry, lies within the non-significant regions of the plot; thus publication bias could be suspected as the main reason for the observed asymmetry. ${ }^{31}$ This notion was confirmed with a significant Egger's test, which indicated the presence of moderate publication bias $(-1.31,95 \%$ $\mathrm{CI}-2.36$ to $-0.27 ; \mathrm{P}=0.018)$. Furthermore, the addition of four "missing" studies imputed using the trim and fill method (white circles in fig 3 ) reduced the magnitude 


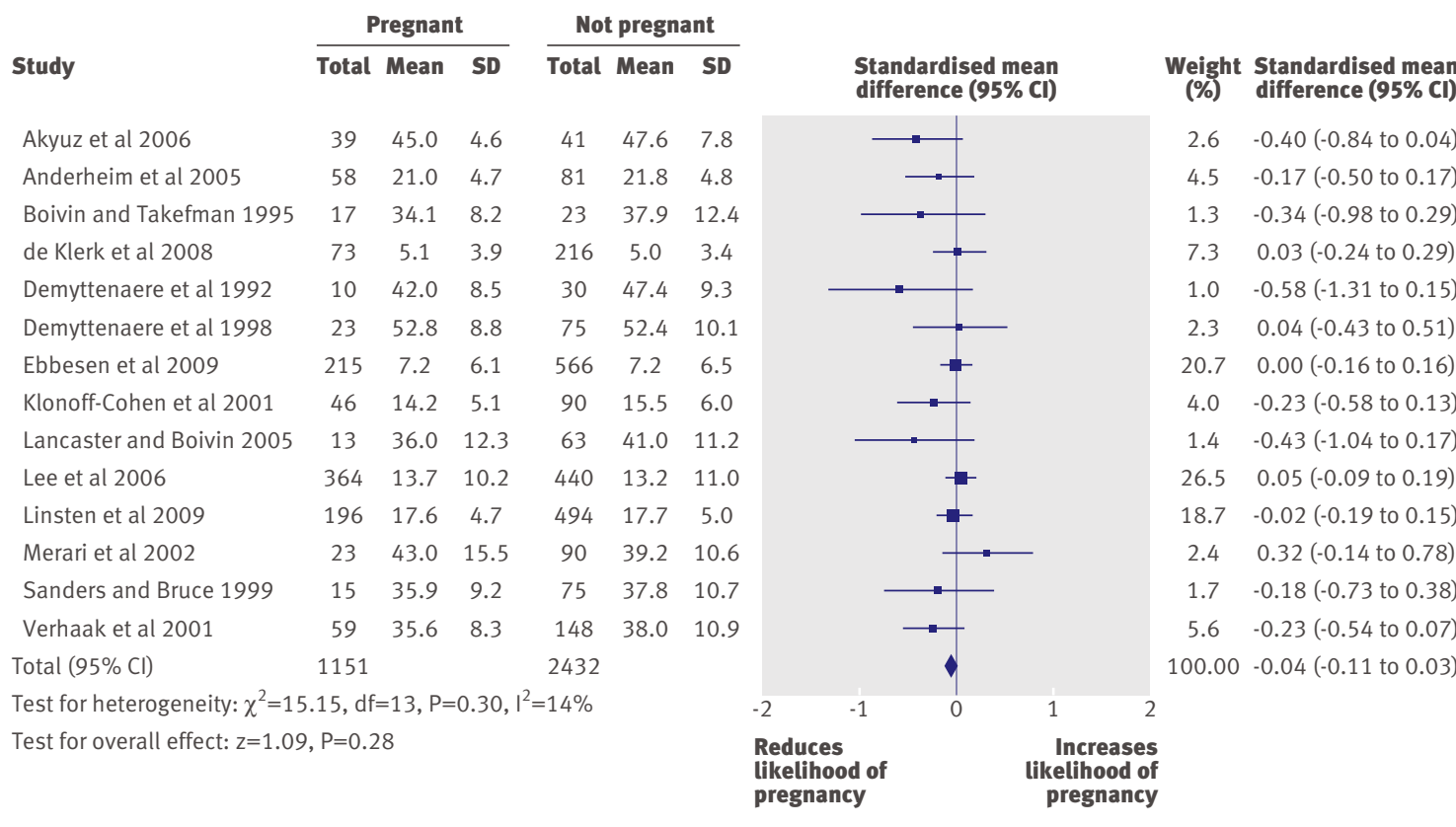

Fig 2 | Means and standard deviations for pretreatment emotional distress in subsequently pregnant and not pregnant women and forest plot of the standardised mean difference in pretreatment emotional distress between groups

of the pooled effect size and shifted it closer to zero (adjusted standardised mean difference $-0.01,95 \%$ CI -0.08 to 0.06 )

\section{DISCUSSION}

\section{Principal findings}

After many decades of research investigating the association between pretreatment emotional distress and the outcome of fertility treatment, this meta-analysis of 14 prospective studies supports the view that emotional distress (for example, feelings of tension, nervousness, or worry) is unlikely to be a cause of failure of fertility treatment. ${ }^{4}$ These findings should reassure women that emotional distress caused by fertility problems or other life events co-occurring with treatment will not compromise their chance of becoming pregnant. Despite these encouraging results, however, definitive research on this psychobiological link is lacking.

The hypothalamic-pituitary-gonadotrophin axis has evolved into a precise system with numerous mechanisms to guard against suboptimal reproductive conditions, including activation of the axis that organises the stress response (the hypothalamic-pituitary-adrenal axis). The fact that total fertility rates are often highest in countries that experience the harsh conditions of war, poverty, and famine ${ }^{42}$ support such a contention. However, evolutionary theory could account for this paradox, ${ }^{43}$ and there is compelling experimental evidence in non-human animals ${ }^{44}$ that these checks do not always work.

\section{Strengths and limitations}

A meta-analysis of this literature was timely and appropriate given that the studies available had low power but generally satisfactory designs, methods, and outcomes. One of the strengths of this review is the comprehensive search strategy that identified a large number of studies from 10 countries. The 14 included studies were generally of average to high quality, with the main methodological weaknesses being use of convenience samples (that is, non-consecutive or selected samples), failure to fully demonstrate the equivalence of the pregnant and not pregnant groups on prognostic indicators before treatment although partial evidence was provided in most included studies), and low power. All included studies measured distress before the start of stimulation, and all assessed outcome after a single cycle of treatment with assisted reproductive technology, precluding the effect of confounding procedural stress ${ }^{7}$ and the effect of variability in the number of assisted reproductive cycles.

The quality of the measurements in the included studies was generally high because well validated and standardised instruments of emotional distress and laboratory or clinical indices of pregnancy were used (except live births). The source studies were published in peer reviewed journals (except for two abstracts). The meta-analysis results showed low heterogeneity between studies (overall $\mathrm{I}^{2}$ index 14\%), whereas the presence of moderate publication bias did not seem to markedly influence the direction or the significance of the observed effect.

This meta-analysis cannot exclude the possibility that psychobiological associations between stress and fertility could be captured using other designs and populations. Assisted reproductive technologies like in vitro fertilisation require multiple external interventions (for example, stimulation with powerful fertility drugs and luteal support during implantation), and the level of emotional distress reported by most patients ${ }^{28}$ may not be sufficient to disrupt a reproductive event supported in this way. Effects (if they exist) 


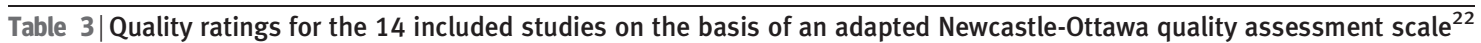

\begin{tabular}{|c|c|c|c|c|c|}
\hline & \multicolumn{4}{|c|}{ Quality criterion } & \multirow[b]{2}{*}{$\begin{array}{l}\text { Overall quality } \\
\text { ratingी }\end{array}$} \\
\hline & Representative* & $\begin{array}{c}\text { Reliably measured } \\
\text { distress } \dagger\end{array}$ & $\begin{array}{l}\text { Comparable on } \\
\text { confounders } \ddagger\end{array}$ & $\begin{array}{l}\text { Adequate outcome } \\
\text { and follow-up§ }\end{array}$ & \\
\hline Akyuz et al $2006^{37}$ & 0 & 1 & 0 & 1 & Low \\
\hline Anderheim et al $2005^{47}$ & 1 & 0 & 0 & 1 & Low \\
\hline Boivin and Takefman $1995^{7}$ & 0 & 1 & 2 & 1 & High \\
\hline de Klerk et al $2008^{40}$ & 1 & 1 & 1 & 0 & Average \\
\hline Demyttenaere et al $1992^{36}$ & 0 & 1 & Not reported & 1 & Low \\
\hline Demyttenaere et al $1998^{35}$ & 0 & 1 & 2 & 1 & High \\
\hline Ebbesen et al $2009^{48}$ & 1 & 1 & 1 & 1 & High \\
\hline Klonoff-Cohen et al $2001^{39}$ & 0 & 1 & 1 & 1 & Average \\
\hline Lancastle and Boivin $2005^{10}$ & 1 & 1 & 1 & 0 & Average \\
\hline Lee et al $2006^{41}$ & 1 & 1 & 0 & Not reported & Low \\
\hline Lintsen et al $2009^{49}$ & 1 & 1 & 1 & 1 & High \\
\hline Merari et al $2002^{38}$ & 0 & 1 & 2 & 1 & High \\
\hline Sanders and Bruce $1999^{34}$ & 0 & 1 & Not reported & 1 & Low \\
\hline Verhaak et al $2001^{20}$ & 1 & 1 & 1 & 1 & High \\
\hline
\end{tabular}

*The representativeness criterion was met when $\geq 80 \%$ of women eligible were invited and $80 \%$ agreed to participate, or when sample size $>300$ ( 1 point).

†The reliability criterion was met when reliable and valid methods were used to assess anxiety or depression (1 point).

†The comparability criterion was met when studies showed evidence that at study entry the pregnant and not pregnant groups were equivalent on the prognostic indicators of age, previous use of assisted reproductive technology, parity, and duration of infertility ( 2 points) or comparable on at least two of these indicators (1 point)

§The quality of outcome and follow-up criterion was met when the completion rate (agreed to participate/analysed) for patients undergoing the cycle was $\geq 80 \%$ (1 point).

IThe overall quality rating was low ( 0 to 2 points), average ( 3 points), or high ( 4 or 5 points).

may be more apparent in untreated (or minimally treated) populations trying to conceive. Indeed, experimental evidence of stress induced reproductive suppression is found only in studies of untreated animals. ${ }^{44}$

The main analytic approach in the included studies was to compare the pretreatment level of distress in subsequently pregnant and not pregnant groups. This approach could have been problematic because the overall prevalence of high anxiety is low even in an infertile population (about $15 \%{ }^{28}$ ), and the prevalence of levels of anxiety capable of disrupting fertility is probably even lower. Averaging emotional distress within outcome groups could therefore dilute associations

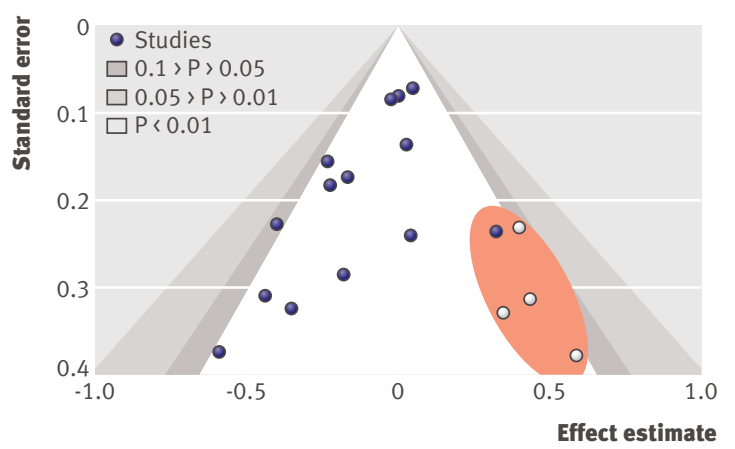

Fig 3 | Contour enhanced funnel plot for meta-analysis of the association between pretreatment emotional distress and achievement of pregnancy in women undergoing a cycle of fertility treatment with an assisted reproductive technology. The red eclipse represents the area where four studies (white circles) were imputed when the trim and fill method was applied because of the predominance of low anxiety participants. An alternative strategy would be to use longitudinal designs and multivariate models (for example, logistic regression) that are capable of prospectively testing whether emotional distress predicts treatment outcome while controlling for potential confounders. It would be imperative for such research to clearly specify the number of treatment cycles, the period of follow-up, or both to allow studies to be compared.

Stress effects may also be more easily detected in specific stages of pregnancy, and there was evidence suggestive of this possibility in our results. The four included studies that defined pregnancy according to a positive pregnancy test during the early implantation stage, when natural conceptions are most likely to fail, ${ }^{13}$ had larger effect sizes than studies that assessed outcome at later stages of pregnancy (that is, by fetal scan or live birth). However, owing to the lack of a plausible theory to account for a stress effect at implantation that is not followed through to later pregnancy, and the fact that these four studies were the smallest of those included in this meta-analysis, small study bias should be considered the most likely cause of the positive associations observed.

Finally, multiple cycles of assisted reproductive technologies are often required to achieve a pregnancy, and stress effects may become more pronounced after repeated treatments. Our subgroup analysis according to previous treatment experience, and other research on the adaptation of the hypothalamic-pituitary-adrenal axis to stress, ${ }^{14}{ }^{15}$ suggest that stress is unlikely to affect the chances of achieving pregnancy in a subsequent cycle. However, emotional distress may reduce the overall chance of success by making couples less 


\section{WHAT IS ALREADY KNOWN ON THIS TOPIC}

The threat of a childless future can produce depressive symptoms (for example, sadness or feelings of loss), and undergoing fertility treatment and its many unfamiliar procedures can cause anxiety (such as worry, tension, and nervousness)

Many infertile women believe that emotional distress is a contributing factor to their lack of natural fertility and lack of success with assisted reproductive technologies, but doctors generally do not hold this belief

Existing human studies on this topic are inconclusive because of significant heterogeneity in study designs

\section{WHAT THIS STUDY ADDS}

This meta-analysis of 14 prospective studies confirms that pretreatment emotional distress is unlikely to affect chances of pregnancy after a single cycle of treatment with assisted reproductive technologies

This finding provides doctors with the evidence to reassure women that emotional distress experienced as a result of fertility problems, their treatment, or other co-occurring life events is unlikely to further reduce chances of pregnancy
Funding: None

Competing interests: All authors have completed the Unified Competing Interest form at www.icmje.org/coi_disclosure.pdf (available on request from the corresponding author) and declare: no support from any organisation for the submitted work for all three authors; EG and CAV declare no financial relationships with any organisations that might have an interest in the submitted work in the previous three years; JB received speaker fees from EMD Serono Inc. and Merck \& Co. (then Schering Plough), and a research grant from Merck Serono S.A. in the previous three years; no other relationships or activities that could appear to have influenced the submitted work for the three authors.

Ethical approval: Not required

Contributors: $\mathrm{B}, \mathrm{EG}$, and CAV contributed to the conception and design of the study. EG and JB discussed search terms and EG executed the search with search experts from Cardiff University. JB and EG both determined eligibility and inclusion of studies and extracted data from the studies, and $\mathrm{B}$ and CAV assessed study quality. EG entered and organised the data, and JB and CAV conducted the analyses and contributed to the interpretation of the data. JB drafted the manuscript, CAV reviewed it for conceptual and analytic integrity, and EG reviewed for accuracy and consistency. JB is the guarantor.

Data sharing: An Excel file of the excluded studies and reasons for exclusion are available from the corresponding author at boivin@cardiff.ac.uk.

willing to stay in treatment for the optimal number of cycles, ${ }^{8}$ and further research is needed to investigate this possibility.

\section{Conclusions and future research}

Overall this meta-analysis indicates a lack of association between pretreatment emotional distress and pregnancy outcome in women undergoing a cycle of treatment with an assisted reproductive technology. This finding provides doctors with the evidence to reassure women that feelings of tension, worry, or depression experienced as a result of their fertility problem, its treatment, or other co-occurring life events are unlikely to further reduce chances of pregnancy. Examining the association between emotional distress and treatment outcome in other populations (for example, untreated populations, or women who receive less invasive treatment or multiple cycles), at different time points in pregnancy, using other outcomes (treatment discontinuation), or using a more suitable analytic approach could widen the applicability of this finding.

Despite the reassurance women can be given about the effects of stress on the likelihood of pregnancy when using assisted reproductive technologies, there is abundant evidence of subclinical and clinical levels of anxiety and depression among infertile women about to undergo these treatments. ${ }^{28}$ As such, patients may still want interventions to improve quality of life during treatment. Interventions that enhance patientphysician communication ${ }^{45}$ or that help patients to cope with the two week waiting period before their pregnancy test ${ }^{46}$ target aspects of treatment known to be particularly demanding and could help maintain quality of life during treatment.

We thank Todd Bailey of Cardiff University for help with the meta-analysis tools used in earlier drafts of this manuscript, and Andrew Kolarik and Stamatis Papaharitou for their help with translation. We thank the authors of the source studies for providing additional information (where relevant). We also thank Christianne Verhaak of Radboud University Nijmegen Medical Centre (Medical Psychology) and Glyn Elwyn from Cardiff University for providing feedback on a first draft of this manuscript.
1 Boivin J, Bunting L, Collins JA, Nygren K. An international estimate of infertility prevalence and treatment-seeking: potential need and demand for infertility medical care. Hum Reprod 2007;22:1506-12.

2 Bunting L, Boivin J. Decision-making about seeking medical advice in an internet sample of women trying to get pregnant. Hum Reprod 2007;22:1662-8.

3 Lord S, Robertson N. The role of patient appraisal and coping in predicting distress in IVF. J Reprod Infant Psychol 2005;23:319-32.

4 Tennen H, Affleck G, Medola R. Causal explanations for infertility and their relationship to control appraisals and psychological perspectives from stress and coping research. Plenum Press, 1991.

5 Nyboe-Andersen A, Goossens V, Ferraretti AP, Bhattacharya S, Felberbaum R, de Mouzon J, et al. Assisted reproductive technology in Europe-2005. Hum Reprod 2009;24:1267-87.

6 Human Fertilisation \& Embryology Authority. Facts and figures 2006: fertility problems and treatment. HFEA, 2008.

7 Boivin J, Takefman JE. Stress level across stages of in vitro fertilization in subsequently pregnant and nonpregnant women. Fertil Steril 1995;64:802-10.

8 Olivius C, Friden B, Borg G, Bergh C. Why do couples discontinue in vitro fertilization treatment? A cohort study. Fertil Steril 2004;81:258-61.

9 Leushuis E, van der Steeg JW, Steures P, Bossuyt PMM, Eijkemans MJC, van der Veen $F$, et al. Prediction models in reproductive medicine: a critical appraisal. Hum Reprod Update 2009;15:537-52.

10 Lancastle D, Boivin J. Dispositional optimism, trait anxiety, and coping: unique or shared effects on biological response to fertility treatment? Health Psychol 2005;24:171-8.

11 Smeenk JM, Verhaak CM, Eugster A, van Minnen A, Zielhuis GA, Braat DD. The effect of anxiety and depression on the outcome of in vitro fertilization. Hum Reprod 2001;16:1420-3.

12 Wasser SK, Barash DP. Reproductive suppression among female mammals: implications for biomedicine and sexual selection theory. Q Rev Biol 1983;58:513-38.

13 Macklon NS, Geraedts JPM, Fauser BCJM. Conception to ongoing pregnancy: the "black box" of early pregnancy loss. Hum Reprod Update 2002;8:333-43.

14 Grissom N, Bhatnagar S. Habituation to repeated stress: get used to it. Neurobiol Learn Mem 2009;92:135-8.

15 Li XF, Edward J, Mitchell JC, Shao B, Bowes JE, Coen CW, et al. Differential effects of repeated restraint stress on pulsatile leutenizing hormone secretion in female fischer, lewis and wistar rats. J Neurobiol 2004;16:620-7.

16 Boivin J, Lancastle D. Medical waiting periods: imminence, emotions and coping. Women Health 2010;6:1-11.

17 Mumford KR. The stress response, psychoeducational interventions and assisted reproduction technology treatment outcomes: a metaanalytic review [Dissertation]. University of South Florida, 2004. reproductive technology (ART): studies on stress, distress and coping [Dissertation]. Aarhus University, 2010.

19 Sandi C, Richter-Levin G. From high anxiety trait to depression: a neurocognitive hypothesis. Trends Neurosci 2009;32:312-9.

20 Verhaak CM, Smeenk JMJ, Eugster A, van Minnen A, Kremer JAM, Kraaimaat FW. Stress and material satisfaction among women before adjustment. In: Stanton AL, Dunkel-Schetter C, eds. Infertility:

18 Matthiesen S. Psychological factors in infertility and artificial 
and after their first cycle of in vitro fertilization and intracytoplasmic sperm injection. Fertil Steril 2001;76:525-31.

21 Zegers-Hochschild F, Nygren KG, Adamson GD, de Mouzon J, Lancaster P, Mansour R, et al. The ICMART glossary on ART terminology. Hum Reprod 2006;21:1968-70.

22 Wells GA, Shea B, O’Connell D, Peterson J, Welch V, Losos M, et al. The Newcastle-Ottawa scale (NOS) for assessing the quality of nonrandomized studies in meta-analysis. The Ottawa Health Research Institute, 2010.

23 Bowling A. Measuring disease. Open University Press, 1995.

24 Hammerli K, Znoj H, Barth J. The efficacy of psychological interventions for infertile patients: a meta-analysis examining menta health and pregnancy rate. Hum Reprod Update 2009;15:279-95.

25 Hedges LV. Distribution theory for Glass' estimator of effect size and related estimators. Journal of Educational Statistics 1981;6:107-28.

26 Fridhandler BM. Conceptual note on state, trait, and the state-trait distinction. J Pers Soc Psychol 1986;50:169-74

27 Folkman S, Lazarus RS. If it changes it must be a process: study of emotion and coping during three stages of a college examination. J Pers Soc Psychol 1985;8:150-70.

28 Verhaak CM, Smeenk JMJ, Evers AWM, Kremer JAM, Kraaimaat FW, Braat DDM. Women's emotional adjustment to IVF: a systematic review of 25 years of research. Hum Reprod Update 2007;13:27-36.

29 Hedges LV, Olkin I. Statistical methods for meta-analysis. Academic Press, 1985.

30 Higgins JPT, Thompson SG, Deeks JJ, Altman DG. Measuring inconsistency in meta-analyses. BMJ 2003;327:557-60.

31 Peters JL, Sutton AJ, Jones DR, Abrams KR, Rushton L. Contourenhanced meta-analysis funnel plots help distinguish publication bias from other causes of asymmetry. J Clin Epidemiol 2008;61:991-6.

32 Egger M, Davey Smith G, Schneider M, Minder CE. Bias in meta analysis detected by a simple, graphical test. BMJ 1997;315:629-34

33 Duval S, Tweedie R. Trim and fill: a simple funnel-plot based method of testing and adjusting for publication bias in meta-analysis. Biometrics 2000;56:455-63.

34 Sanders KA, Bruce NW. Psychosocial stress and treatment outcome following assisted reproductive technology. Hum Reprod 1999;14:1656-62.

35 Demyttenaere K, Bonte L, Gheldof M, Vervaeke M, Meuleman C, Vanderschueren D, et al. Coping style and depression level influence outcome in IVF. Fertil Steril 1998;69:1026-33.

36 Demyttenaere K, Nijs P, Everskiebooms G, Koninckx PR. Coping and the ineffectiveness of coping influence the outcome of in vitro fertilization through stress responses. Psychoneuroendocrinology 1992;17:655-65

37 Akyuz A, Gurhan N, Atici D. The effect of male and female depressionanxiety levels on oocyte-sperm number and pregnancy rates during IVF treatment [abstract]. Hum Reprod 2006;21:i72-3.

38 Merari D, Chetrit A, Modan B. Emotional reactions and attitudes prior to in vitro fertilization: an inter-spouse study. Psychol Health 2002;17:629-40.

39 Klonoff-Cohen H, Chu E, Natarajan L, Sieber W. A prospective study of stress among women undergoing in vitro fertilization or gamete intrafallopian transfer. Fertil Steril 2001;76:675-87.

40 De Klerk C, Hunfeld JAM, Heijnen E, Eijkemans MJC, Fauser B, Passchier J, et al. Low negative affect prior to treatment is associated with a decreased chance of live birth from a first IVF cycle. Hum Reprod 2008;23:112-6.

41 Lee A, Duckworth AL, Elkind-Hirsch KE, Seligman ME, Scott JRT. Negative emotion predicts poor outcome in poor prognosis IVF patients [abstract]. Fertil Steril 2006;86:S55-6.

42 Agadjanian V, Prata N. War and reproduction: Angola's fertility in comparative perspective. J S Afr Stud 2001;27:329-47.

43 Boivin J, Sanders K, Schmidt L. Age and social position moderate the effect of stress on fertility. Evol Hum Behav 2006;27:345-56.

44 De Catanzaro D, MacNiven E. Psychogenic pregnancy disruptions in mammals. Neurosci Biobehav Rev 1992;16:43-53.

45 Tuil WS, ten Hoopen AJ, Braat DDM, de Vries Robbé PF, Kremer JAM. Patient-centred care: using online personal medical records in IVF practice. Hum Reprod 2006;21:2955-9.

46 Lancastle D, Boivin J. Feasibility, acceptability and benefits of a selfadministered positive reappraisal coping intervention (PRCl) card fo medical waiting periods. Hum Reprod 2008;23:2299-307.

47 Anderheim L, Holter H, Bergh C, Moller A. Does psychological stress affect the outcome of in vitro fertilization? Hum Reprod 2005;20:2969-75.

48 Ebbesen SMS, Zachariae R, Mehlsen MY, Thomsen D, Højgaard A, Ottosen L, et al. Stressful life events are associated with a poor invitro fertilization (IVF) outcome: a prospective study. Hum Reprod 2009;24:2173-82.

49 Lintsen AME, Verhaak CM, Eijkemans MJC, Smeen JMJ, Braat DDM. Anxiety and depression have no influence on the cancellation and pregnancy rates of a first IVF or ICSI treatment. Hum Reprod 2009;1:1-7.

Accepted: 02 November 2010 